\title{
Cultura, língua e literatura em Milagrário pessoal, de José Eduardo Agualusa
}

\author{
Culture, language and literature in Milagrário Staff, José Eduardo Agualusa
}

\author{
JOSÉ LUÍS GIOVANONI FORNOS \\ Universidade Federal do Rio Grande
}

-

\begin{abstract}
Resumo: O presente ensaio examina a narrativa Milagrário pessoal, do escritor angolano José Eduardo Agualusa, considerando a presença da língua portuguesa e seu diálogo com a literatura numa dimensão multicultural. No estudo, predomina a recuperação de episódios e passagens problematizadores da ideia de uma identidade nacional fixa e homogênea, tema recorrente na obra do autor. Por fim, o trabalho insere o romance de Agualusa numa perspectiva pós-colonial.
\end{abstract}

Palavras-chave: Língua Portuguesa; cultura literária; identidade nacional.

\begin{abstract}
This study examines the novel Milagrário pessoal ("Personal notebook of miracles") by the Angolan writer José Eduardo Agualusa, considering the presence of the Portuguese language and its dialogue with the literature in a multicultural dimension. Predominantly the study recovers episodes and passages questioning the idea of a fixed and homogenous national identity, a recurring theme in Agualusa's works. Finally the study gives the novel a post-colonial perspective.
\end{abstract}

Keywords: Portuguese language; literary culture; national identity.

O romance Milagrário pessoal (2010), de José Eduardo Agualusa, dá continuidade a temas que demarcam a obra do escritor angolano. Entre esses se destacam a rememoração crítica dos processos históricos de seu país - as chamadas guerras coloniais de libertação e os conflitos civis internos de Angola -; a problematização das fronteiras entre o ficcional e o histórico; o questionamento da categoria étnico-racial; a apreciação das identidades nacionais; o diálogo das culturas afro-ibérico-americanas e asiáticas; ênfase à tradição oral; os intertextos vinculados ao cânone de língua portuguesa na África; o tratamento dado à figura feminina e o enfoque positivo à mestiçagem cultural, assinalada pelos deslocamentos geográficos.

Este último tema ecoa nas proposições da crítica póscolonial. Tal corrente epistemológica tem como marco o livro Orientalismo (1978), de Edward Said que se dispõe a "ilustrar a formidável estrutura da dominação cultural e, especificamente para os povos outrora dominados, os perigos e tentações de se empregar essa estrutura sobre si mesmo e sobre os outros" (SAID, 1990, p.36). Nela Said interroga o modo como a narrativa ocidental, mais especificamente a europeia, representou e continua a representar o Oriente. O estudioso palestino observa a representação binária que dividiu o mundo em Nós, o europeu, o ocidental, o civilizado, o colonizador, e o Outro, o não-europeu, o oriental, o bárbaro, o colonizado ${ }^{1}$.

Said ressalta que o poder imperial não se limita ao contexto geoeconômico, intervindo com mais intensidade no âmbito cultural e intelectual, uma vez que àquele que dominava cabia o papel de narrar. O livro Orientalismo pôs em questão a representatividade não só de povos colonizados, mas igualmente a todo e qualquer questionamento acerca da subalternidade. Com tal tese, veio à tona o fato de que, grosso modo, apenas um lado da história havia sido ou vinha sendo contado e que o vazio representacional deixado pelas grandes narrativas imperiais precisava de algum modo ser preenchido.

\footnotetext{
1 Segundo a avaliação de Sérgio Costa, os estudos pós-coloniais "não constituem propriamente uma matriz teórica única." Trata-se, segundo o autor, "de uma variedade de contribuições com orientações distintas, mas que apresentam como característica comum esforço de esboçar, pelo método da desconstrução dos essencialismos, uma referência epistemológica crítica às concepções dominantes da modernidade.” A
} 
Em última instância, a chamada crítica Pós-Colonial pretende abalar o modo como as narrativas dos centros europeus hegemônicos representam o Outro, incentivando a divulgação do que está ausente na historiografia e no cânone literário. Tal mudança de âmbito epistemológico propõe a reescritura dessa história "perdida" com base na experiência dos povos dominados pelo Imperialismo, vítimas do sistema colonial, sujeitos não apenas à exploração econômica, mas à supressão de sua memória e à depreciação de suas culturas. Nesse sentido, "o que caracterizaria uma situação pós-colonial seria uma relação de insuficiência representacional, ou seja, uma incapacidade crônica dos sujeitos de expor sua própria narrativa sobre os fatos" (MACHADO, 2004, p.20).

A episteme pós-colonial absorve de maneira crítica o passado colonial, testemunhando acerca das "forças desiguais e irregulares de representação cultural", intervindo "nos discursos ideológicos da modernidade que tentam dar uma normalidade hegemônica ao desenvolvimento das histórias diferenciadas de nações, raças, comunidades, povos" (BHABHA, 1998, p. 239). São processos críticos de interação cultural que podem ser compreendidos como zonas de contato, tal como foi exposto por Mary Louise Pratt $(1999)^{2}$. O deslocamento de pessoas, ideias e textos cumpriria uma função primordial, gerando processos de transculturação em distintos espaços nacionais. ${ }^{3}$

Por meio dos deslocamentos é que podem prosperar os contatos cujos resultados, para uma crítica pós-colonial, devem ser dimensionados à luz do que Aníbal Quijano chama de colonialidade do poder. Para o autor, um dos elementos constitutivos desta colonialidade é "o padrão mundial do poder capitalista" (QUIJANO, 2009, p. 73.) Dessa forma, está associada à evolução de tal poder, a ideia de modernidade, projetada a partir do território europeu. $\mathrm{Na}$ visão do estudioso peruano:

\footnotetext{
2 De acordo com Mary Louise Pratt, seu livro "foi concebido dentro de um amplo desafio intelectual que se poderia chamar de descolonização do conhecimento, iniciado nos anos 60 pela desintegração da última onda de impérios coloniais europeus." Para a autora, a "descolonização do conhecimento inclui a tarefa de chegar a compreender os caminhos pelos quais o Ocidente (a) constrói seu conhecimento do mundo, alinhado às suas ambições econômicas e políticas, e (b) subjuga e absorve os conhecimentos e as capacidades de produção de conhecimentos outros." $(1999$, p. 15)

3 Para Fernando Ortiz, a transculturação é um processo cultural-social em que as diversas culturas se fundem na vida cotidiana e na cultura. $\mathrm{O}$ conceito foi adaptado à literatura por Angel Rama (Transculturação narrativa em América Latina, México, Siglo XXI, 1982). Para Rama, a transculturação aparece como uma mestiçagem cultural; ocorre entre a alta cultura e a subalterna, está a cargo de uma vanguarda de escritores e críticos e se relaciona à identidade nacional e ao estabelecimento e consolidação do Estado. In: LUDMER, Josefina. O gênero gauchesco: um tratado sobre a pátria. Chapecó; SC: Argos, 2002.
}

A colonialidade do poder e a dependência histórico-estrutural implicam ambas a hegemonia do eurocentrismo como perspectiva epistemológica. No contexto da colonialidade do poder, a população dominada, nas novas identidades que lhes haviam sido atribuídas, foram também submetidas à hegemonia eurocêntrica como maneira de conhecer, na medida em que alguns de seus setores puderam aprender a língua dos dominadores. Portanto, o eurocentrismo não é exclusivamente a perspectiva cognitiva dos europeus, ou apenas dos dominantes do capitalismo mundial, mas também do conjunto dos educados sob sua hegemonia (QUIJANO, 2009, p. 74-75).

$\mathrm{Na}$ explanação de Quijano, há um elemento importante que deve ser considerado: todos passam a estar envolvidos de alguma maneira frente à expansão global do capitalismo ou como assinala: "educados sob sua hegemonia". Sob os efeitos dessa, a divisão entre metropolitanos e periféricos deve ser examinada a partir das complexidades e contingências das relações de poder que se encontram cada grupo e indivíduo, criando uma variação de posições no seio de cada nação e sociedade.

Neste caso, são importantes as reflexões e reivindicações teóricas de Paul Gilroy ao defender a tese de um Atlântico negro como unidade de análise única e complexa do mundo moderno para produzir uma perspectiva transnacional e intercultural, em oposição às abordagens nacionalistas ou etnicamente absolutas. A história do Atlântico negro "propicia um meio para reexaminar os problemas de nacionalidade, posicionamento, identidade e memória histórica" (GILROY, 2008, p. 59).

Homi Bhabha (1998) referenda tais propósitos com a seguinte assertiva: "a cultura como estratégia de sobrevivência é tanto transnacional como tradutória" (p.241). A defesa do transnacional como categoria analítica ocorre porque os discursos contemporâneos "estão enraizados em histórias específicas de deslocamento cultural" (p.241). Em relação à categoria da tradução, Bhabha escreve que não é a de "transportar fatias suculentas de sentido de um lado da barreira de uma língua para a outra", mas observar como "as histórias espaciais de deslocamento tornam a questão de como a cultura significa, ou o que é significado por cultura" (BHABHA, 1998, p. 248). A dimensão transnacional da transformação cultural, assinalada pela migração, diáspora, deslocamento e retorno, "torna o processo de tradução uma forma complexa de significação" (p.241). A mobilidade de indivíduos e comunidades configura novas territorialidades, perturbando a mecânica dos pertencimentos.

É preciso destacar que Milagrário pessoal potencializa aspectos acima mencionados, proporcionando igualmente 
o estudo de categorias como viagem ${ }^{4}$, encontro e contato . $^{5}$ Elas reaparecem, agora, sob o feito e determinação da língua portuguesa. No romance, as palavras da nossa língua circulam em diferentes ambientes, tornando-se como elemento estruturador do livro à medida que passa a funcionar como personagem sociocultural.

Desde as primeiras páginas, os vocábulos são, ao mesmo tempo, objeto de reflexão e motivadores do enredo. Igualmente estimulam as ações das demais personagens, configurando a identidade dos indivíduos, das comunidades e das nações. A língua realça culturas, ganhando poder de troca e intervenção criativa, tornando-se um dos pilares da manifestação identitária. Abre zonas de conflito e solidariedade. Aponta para a hibridação.

Em que pese suas múltiplas potencialidades, é no campo da cultura, oral e letrada, que a língua adquire valor no romance. Ela é geradora das relações sociais e interculturais, culminando, simultaneamente, em fator de discórdia e entendimento. Ao mesmo tempo, proporciona descobertas surpreendentes, alterando a rígida divisão dos mapas nacionais. Também faz reviver a paixão, reinventando encontros de diferentes gerações. Suspende a objetividade, diluindo verdades e mentiras.

É por meio da língua que as culturas, os homens, os textos e as ideias viajam no tempo, encontrando acolhida em diferentes lugares e períodos. Também sinaliza para novas aprendizagens, buscando a interação, a convivência,

\footnotetext{
4 As viagens voluntárias e involuntárias proporcionaram "uma literatura abundante; coisas vistas e ouvidas, contadas oralmente ao retorno, que puderam fecundar imaginações; ou consignadas no papel, em formas diversas, desde as simples notas rabiscadas num pequeno caderno até o relato de viagem, passando pelo diário de viagem e pela carta, sem esquecer o panfleto enraivecido. Obras fundamentais focalizam os intercâmbios internacionais, a psicologia dos povos, a constituição de mitos de um novo gênero, a renovação do pensamento de um escritor ou as idéias-mestras de uma literatura" (BRUNEL, PICHOIS e ROUSSEAU. Que é literatura comparada? São Paulo: Perspectiva, 1995).

5 O motivo do encontro é um dos aspectos que caracteriza a cronotopia bakhtiniana. Para o autor russo, "o motivo do encontro recebe matizes diferentes e concretos, inclusive emocionais e de valor", podendo assumir um significado semi ou totalmente metafórico, tornando-se, por fim, um símbolo. O cronotopo do encontro exerce, em literatura, funções composicionais, servindo de nó ou mesmo desfecho do enredo. Para Bakhtin, o "encontro é um dos mais antigos acontecimentos formadores do enredo", em particular do romance, devendo-se observar a "estreita ligação do motivo do encontro com motivos da separação, a fuga, o reencontro, a perda, o casamento". É preciso ressaltar igualmente a ligação de tal cronotopo com o da estrada o que nos leva a refletir sobre a situação do deslocamento e da viagem. Cabe, aqui, a questão não abordada por Bakhtin, embora sugerida, sobre a caracterização da cronotopia do encontro e da estrada no chamado romance pós-colonial. Atento à caracterização histórico-formal do romance, Bakhtin, todavia, enfatizando o romance antigo, minimiza o sentido político e geográfico da cronotopia. Nesse sentido, acrescenta que, "é importante passar a um outro país, mas qual será esse outro país também é absolutamente indiferente. As peripécias aventurosas do romance grego não têm quaisquer ligações substanciais com as particularidades de cada país que figura no romance, com sua estrutura sócio-política, sua cultura, sua história" (BAKHTIN, 1998, p. 224).
}

através do afeto e do conhecimento. A língua portuguesa como ponte das trocas culturais é imagem persistente em Milagrário.

Assim, no próprio subtítulo, assinalado entre parênteses, tem-se o conhecimento prévio dos temas da obra. Diz: Apologia das varandas, dos quintais e da língua portuguesa, seguida de uma breve refutação da morte. Tais elementos informarão o quanto as sociedades estão entrelaçadas, ainda que, para alguns, sejam entrevistas separadamente. Um conto tradicional ovimbundo, extraído do livro Selecção de contos, provérbios e advinhas em umbundo, de Jeremias Capitango, dá partida a uma das muitas polêmicas teses do narrador e também personagem principal: os homens aprenderam a falar com os pássaros. A seguir, na abertura do primeiro capítulo, uma breve nota introdutória antecipa o tema a ser tratado:

A neologista, e o curioso ofício de caçar, colecionar e classificar palavras novas, como um entomologista caça, coleciona e classifica coleópteros. Este capítulo versa também sobre a instalação dos milagres no cotidiano das pessoas, prodígios domésticos, quase secretos, de cujo fulgor pouca gente se apercebe (p. 13).

O narrador, um velho filólogo angolano que esteve sempre ligado ao estudo de neologismos, escreve em seu diário:

As palavras, como os seres vivos, nascem de vocábulos anteriores, desenvolvem-se e fatalmente morrem. As mais afortunadas reproduzem-se. Há as de índole agreste, cuja simples presença fere e desagrada, e outras que de tão amoráveis tudo à sua volta suavizam. Estas iluminam, aquelas confundem. Umas são selvagens, irascíveis, cheiram mal dos pés, fungam e cospem no chão. Outras, logo ao lado, parecem altivas e delicadas orquídeas (p. 15).

Após, o mesmo narrador apresenta a personagem Iara, uma estudante de línguas, dedicada à caça de neologismos. A aproximação gera cumplicidade afetiva, alimentada pelo prazer em torno do conhecimento das palavras que acaba por desencadear uma paixão no velho professor.

A jovem estudante e ex-modelo Iara, preocupada em "encontrar eventuais neologismos", vai recolhendo palavras não dicionarizadas nos jornais diários disponíveis na internet. O seu ex-professor, o octogenário angolano, sensibilizado com o empenho da moça, entusiasma-se, ajudando-a na pesquisa. Através de um diário intitulado Milagrário pessoal o angolano, exilado em Lisboa, anota o que chama de fatos prodigiosos ocorridos no dia-a-dia que poucos percebem ou importância dão: 
Vou anotando nas páginas do meu Milagrário pessoal os fatos extraordinários que me sucedem, ou de que sou involuntária testemunha, dia após dia. É um diário de prodígios. Os milagres acontecem a cada segundo. Os melhores costumam ser discretos. Os grandes são secretos (p. 18).

O elo inicial entre as duas personagens é o interesse pelas palavras. O texto literário é um dos espaços reprodutores da cultura e da língua de suas sociedades. Os escritores mencionados pelo velho narrador pertenceriam a uma espécie de academia de logótetas. Em tal instituição, estariam incluídos os brasileiros Guimarães Rosa e Manoel de Barros, o poeta do Pantanal que, segundo o narrador, disse que "os homens precisam reaprender a errar a língua" (p.26). Ainda aparecem o angolano José Luandino Vieira e o moçambicano Mia Couto. A jovem Iara irrita-se com o velho professor quando este ironiza, provocando que, em tal academia, não haveria escritores portugueses.

Os capítulos seguintes se desdobram sempre a partir de textos que vão sendo relembrados e lidos, incorporando-se à estrutura narrativa. Assim, na sua biblioteca de aproximadamente 25 mil livros, o narrador se depara com um tratado de autoria de Domingos Ferreira da Assumpção, conhecido como Quitubia, cujos estudos referem-se à rainha Ginga, figura central na história de Angola. Quitubia reaparece como personagem na épica de Basílio da Gama.

A presença de Camilo Castelo Branco igualmente recebe destaque quando o narrador adverte acerca do interesse do escritor pela cultura popular. Essa disposição está expressa na correspondência encontrada pelo narrador nos objetos de sua mãe falecida. As cartas revelam o contato entre Camilo e o conhecido ladrão Zé do Telhado com quem o escritor dividira a cela quando esteve preso em virtude do caso Ana Plácido. Segundo o narrador, a qualidade da prosa camiliana se deve a sensibilidade do autor em fazer uso de palavras advindas do meio popular, ouvidas na prisão pela voz do delinquente.

Desta forma, o texto de Agualusa vai forjando, paralelamente aos acontecimentos vividos por Iara e o professor, uma cadeia textual. Tal sequência leva os dois protagonistas a uma viagem ao Brasil, mais especificamente à cidade de Olinda, em Pernambuco, a fim de informar-se sobre as palavras que foram empregadas por uma jornalista, editora do Caderno de Viagens do jornal português $O$ Público.

Em Olinda, conhecem o poeta local Alexandre Anhanguera, mencionado na reportagem da jornalista Mara Bruto da Costa. O poeta é contrário ao emprego de estrangeirismos na língua portuguesa. $\mathrm{O}$ encontro com Anhanguera revela um elemento recorrente nas narrativas de Agualusa: personalidades históricas que se misturam ao universo ficcional, borrando as fronteiras entre realidade e ficção.

Em Milagrário, é Luís Arraes, amigo do narrador, que se soma às demais personagens. Luís é filho do falecido político Miguel Arraes. Este último esteve exilado no período do regime militar. Ao retornar ao Brasil, governou o estado de Pernambuco.

Ao chegarem ao Brasil, Iara e o professor, além dos contatos para dar prosseguimento à pesquisa, comentam acerca das características culturais e arquitetônicas do lugar e do país, comparando-as com as cidades de Lisboa e as dos países africanos de língua portuguesa.

Um dos traços evocados para o estabelecimento comparativo é a origem de determinadas palavras. Numa conversa com Iara, o professor provoca a moça, sugerindo que a mesma faça uma lista de vocábulos que ela considera belos. Minutos antes, a estudante mostrara algumas: afago; açucena; lume; pitanga; langue; morena; morança; desamparinho.

Iara brinca com o professor chamando a atenção de duas palavras que seriam originárias do português de África. O professor corrige-a, acrescentando outras informações:

\begin{abstract}
Pitanga não tem origem africana, vem do tupi e significa avermelhado; quissange, sim. Açucena e afagar são de proveniência árabe. Morança é um termo do crioulo guineense, designando agregado familiar. A palavra desamparinho, uma das mais belas do crioulo cabo-verdiano, dá nome àquela hora feliz, ao final da tarde, quando o dia cede lugar à noite, o calor esmorece e os velhos se sentam nos passeios, fruindo o fresco e as cigarras, e vendo as moças passarem sacudindo as ancas $(2010$, p. 71).
\end{abstract}

Rebatendo ao protesto de Iara que declara que só valem palavras portuguesas, o professor exclama:

São palavras portuguesas! Os crioulos de base portuguesa, como aqueles que existem em Cabo Verde, Guiné-Bissau, São Tomé e Príncipe ou em Casamance, no Senegal, todos eles preservam termos de nossa língua (p. 70).

$\mathrm{Na}$ sequência, em forma de brincadeira, nova lista de palavras é organizada. O professor chama a atenção para murmurinho, "uma expressiva onomatopeia com que em latim se pretendia reproduzir o redondo do rumor do mar." (p.71) Diz ainda apreciar o termo afeiçoar:

Gosto desta palavra; afeiçoar, e seu duplo sentido: tanto significa desenvolver afeto como moldar-se. Por que é isto o que acontece - quando nos afeiçoamos à alguém ou alguma coisa vamos ganhando pouco a pouco a forma dessa pessoa ou dessa coisa (p. 71). 
Diante da beleza e dos seus efeitos, o professor conclui: "Assim como nós criamos as línguas, também as línguas nos criam a nós" (p.72). Com ironia, procura estender tal tese, sem generalizá-la, às nações: "não custa atribuir a obstinada melancolia dos portugueses ao uso desregrado da palavra saudade, no fado, na poesia, no discurso dos filósofos e dos políticos". Para o professor, "seria interessante estudar o quanto o culto à saudade contrariou, vem contrariando, o esforço para desenvolver Portugal" (p. 73).

Em contrapartida, "a famosa arrogância e o otimismo dos angolanos poderiam dever-se à insistência em termos de bué, futuro, esperança ou vitória" (p. 73). Em relação à identidade nacional brasileira, acrescenta:

No que respeita à alegria dos brasileiros, poderíamos talvez imputá-la a duas ou três palavras fortes que acompanham desde há muito a construção e o crescimento do país: mulato/mulata, bunda, carnaval (p. 73).

Outros aspectos da identidade cultural são mencionados no decorrer da narrativa. Na chegada à pousada em Olinda, o professor faz referência à varanda do lugar, elemento expresso no subtítulo do romance. Ao comentar sobre tais engenhos arquitetônicos, recorda que o pai denominava-as de pensadouros. "Aprendi com ele a amar as varandas, bem como a alpendres, miradouros, lugares elevados de uma forma geral" (p. 79). As varandas são espaços propícios para a contemplação, completa o narrador. $^{6}$

Sobre os quintais - elemento tratado no décimo primeiro capítulo - lê-se: "breves notas para um ensaio sobre o papel dos quintais nas sociedades crioulas de matriz portuguesa nos trópicos." (p. 154). Ao referir-se sobre o assunto, o narrador recorre a Mário Pinto de Andrade, importante intelectual angolano, antigo membro do MPLA já falecido, que ao ser questionado sobre a relação entre o português e a língua quimbundo, afirmava: "quando criança, o português era a língua da casa e o quimbundo o idioma do quintal" (p.157). Também ao narrador aconteceu-lhe algo semelhante: "cresci entre a sala de estar e o quintal" (p. 157). Na sala de estar, falava-se o português, no quintal utilizava-se o quimbundo. Ao corroborar a dupla identidade, o narrador diz concordar com Amin Maalouf que, no ensaio identidades assassinas, postula: "quanto mais identidades partilhamos, mais singulares nos tornamos". Tal partilha identitária era proporcionada pela convivência nos quintais.

\footnotetext{
6 Para um estudo suplementar, ver as obras do sociólogo pernambucano Gilberto Freyre dedicadas ao assunto com destaque para Oh de casa! (1979).
}

Em Luanda, no Dundo, na Chibia, os quintais foram desde sempre espaços amáveis de convívio e de permuta. Organizavam-se longos e alegres almoços de sábado à sombra refrescante de mangueiras e mulembeiras (p.158).

Todavia, segundo o narrador, Mario Pinto de Andrade esquecera-se de acrescentar que nos quintais de Luanda, o quimbundo misturava-se com o português. No Brasil, escreve o narrador:

O quintal foi durante séculos o lugar onde a África repousava do esforço escravo. Ali, contavam-se histórias, cultuavam ancestrais e orixás, e se festejava a vida. Em Salvador, no Recife, São Luís do Maranhão, Ouro Preto ou no Rio de Janeiro a nossa língua convivia com os idiomas indígenas e africanos (p.159).

O narrador diz ter um gosto especial em adentrar nos quintais seja na África ou no Brasil:

Gosto de entrar por esses quintalões antigos, em Olinda ou em Benguela, afagando os cansados muros de adobe, afastando as pesadas folhas de bananeira e humidade ofegante, para finalmente sentar no chão, a cabeça encostada ao tronco rugoso de alguma árvore centenária. Um abacateiro. Uma mangueira. Uma figueira. Um pau de fruta-pão. Fecho os olhos e logo um vago rumor de vozes ascende da terra negra (p. 159).

No retorno a Lisboa, novas incursões do narrador à pesquisa - correspondência de Camilo com José do Telhado, salteador popular do século XIX, em degredo em Angola - revelam a imbricação da cultura africana com a portuguesa. Igualmente, o narrador expõe as motivações do seu afastamento de Angola, comentando as mazelas do regime instaurado logo após o onze de novembro de 1975, data de libertação nacional do país:

Nenhuma guerra liberta, insurgi-me. A violência aprisiona os seus perpetadores num ciclo de ódio. Não foi por acaso que todas as antigas colônias onde houve guerras ditas de libertação mergulharam após as independências em novas guerras. No caso de Angola, aquilo a que nós chamamos guerra de libertação, e os portugueses guerra colonial, começou por ser um massacre, organizado pela União dos Povos de Angola, UPA, um movimento bacongo, que nada tinha de progressista, contra fazendeiros portugueses, as respectivas famílias e os trabalhadores ovimbundos. Durante catorze anos, até a Revolução dos Cravos, os guerrilheiros do MPLA combateram tanto os da UPA e os da UNITA quanto os soldados portugueses. Por outro lado, a partir de uma certa altura, a tropa colonial começou a incorporar angolanos. Milhares de angolanos Quem está hoje à frente do exército governamental? Generais que combateram na época colonial ao lado dos portugueses (p. 191). 
No exílio, o professor continua a provocar polêmicas, defendo teses que contrariam governos e nacionalidades:

Em relação a Portugal, afirma:

Os portugueses são medrosos. Eu disse medrosos. Os portugueses com coragem e ambição foram-se embora nas caravelas, a construir mundos, a destruir outros mundos. Ficaram os velhos do Restelo, coitados, sempre a queixarem-se da crise e do reumatismo, e a transmitirem muito a custo os fracos genes, além do medo, às gerações vindouras (p. 197).

Para a personagem os sentidos da pátria se vinculam ao ser através da memória geográfica e familiar:

Minha pátria é um mistério íntimo. Penteio seus cabelos longos e ásperos no frio crepúsculo do meu quarto. Minha pátria é um rumor esparso. Os Ngola Ritmos cantando Muxima, e já todos mortos, ou quase todos. Meninos levantando papagaios de papel num céu muito azul, e nenhum fui eu. As nuvens nas quais vi desenhado o meu futuro, e que logo se esfumaram. A minha mãe costurando numa velha máquina Singer o fato que o meu pai nunca chegou a vestir. A minha pátria é uma dor fantasma, como a ferida latejando na perna do jovem soldado, muito depois de lhe cortarem a perna (p.190).

Depois de inúmeras polêmicas e vários conflitos, em diferentes períodos de sua vida, o narrador confessa, com ironia e oportunismo, que a viagem ao Brasil em busca dos estudos acerca das línguas e de novos neologismos fora uma fraude, articulada entre ele, a jornalista e os poetas. Combinara inicialmente com Mara Bruto. Depois entrara em contato com Alexandre Anhanguera e Plácido Domingo que não passavam de personagens construídas com a finalidade de seduzir a jovem Iara, como sublinhara o próprio Anhanguera.

Procurando contrapor-se ao natural envelhecimento do corpo, "Horroriza-me assistir ao lento declínio do meu corpo" (p.228), o velho conquistador angolano apelara para o conhecimento, única forma de aproximação com a moça. Num instante, apaixonara-se, imaginando situações e cenas que gostaria de partilhar com Iara:

Penso em todos os lugares que gostaria de visitar contigo. No que gostaria de fazer contigo - e não farei nunca:

Ler-te alto as Ficções, de Borges.

Rir, enquanto nadássemos entre golfinhos, no mar sem maldade de Fernando de Noronha.

Dormir no deserto.

Cozinhar-te um bom muzonguê, seguindo a receita que me deixou a minha mãe
Ensinar-te as palavras mais meigas da língua umbundo ( a língua mais meiga do mundo).

Ensinar-te a flutuar no mar liso do Mussulo (Ilhéu dos Padres).

Ensinar-te a dançar tango.

Ouvir-te discorrer sobre a arte de caminhar dos manequins.

Fotografar-te nua.

Beijar os teus lábios depois de comermos juntos sorvetes de pitanga.

Ver contigo Deus e o diabo na terra do sol, do Glauber Rocha. Aliás, ver contigo a filmografia completa do Glaber Rocha.

Desenhar, e depois construir, a casa perfeita.

Voar num balão sobre montanhas de Huíla e o deserto do Namibe.

Passear de mãos dadas, no Parque Guell, em Barcelona. Etc., etc, tantas são as coisas que não faremos nunca (p.221).

Ao final da narrativa, contrata um candongueiro angolano, de apelido Beija-Flor, - referente à Escola de Samba do Rio de Janeiro - para conduzi-lo ao interior de seu país de origem, revisitando espaços de sua infância em que rememora os banhos nos rios e caçadas de pássaros, procurando enfrentar o temor do esquecimento. Assim, nas páginas finais questiona: "quantas lembranças perdemos por segundo?” (p. 228).

O questionamento restitui uma das diretrizes do pensamento crítico historiográfico que, através da memória, pretende impedir o aniquilamento das comunidades ecológicas e culturais - os seus modos de ser e viver. Nessa perspectiva, as palavras e os textos literários funcionam como pequenos milagres, reconfigurando a identidade dos povos numa dimensão multicultural, tese que vem alicerçando o universo dos romances de José Eduardo Agualusa.

\section{Referências}

AGUALUSA, José Eduardo. Milagrário pessoal. Rio de Janeiro: Língua Geral, 2010.

BAKHTIN, Mikhail. Questões de estética e de literatura. São Paulo: Hucitec, 1997.

BHABHA, Homi. O local da cultura. Belo Horizonte: UFMG, 1998.

BRUNEL, P.; PICHOIS, C.L.; ROUSSEAU, A.M. Que é literatura comparada? São Paulo: Perspectiva, 1995.

COSTA, Sérgio. Dois Atlâticos: teoria social, anti-racismo, cosmopolitismo. Belo Horizonte: UFMG, 2006.

GILROY, Paul. $O$ atlântico negro. Rio de Janeiro: Editora 34, 2008.

LUDMER, Josefina. O gênero gauchesco: um tratado sobre a pátria. Chapecó, SC: Argos, 2002. 
MACHADO, Igor J.R. Reflexões sobre o Pós-Colonialismo. Teoria e Pesquisa. Revista de Ciências Sociais, UFSCAR, São Paulo, v. 1, n. 44, p. 19-32, 2004.

PRATT, Mary Louise. Os olhos do império: relatos de viagem e trasculturação. Bauru, São Paulo: EDUSC, 1999.

SAID, Edward. Orientalismo. São Paulo: Companhia das Letras, 1990.
SANTOS, Boaventura de Sousa e MENEZES, Maria Paula. (Org.) Epistemologias do sul. Coimbra: Almedina, 2009.

Recebido: 29 de janeiro de 2016 Aprovado: 27 de maio de 2016 Contato: jlgf@vetorial.net 